\title{
Calculation of temperature and velocity fields in the furnace chambers of tube ovens
}

\author{
A. V. Sadykov ${ }^{1, *}$, and D. B. Vafin ${ }^{1}$ \\ ${ }^{1}$ Nizhnekamsk Chemical Technological Institute (branch) of Kazan National Research Technological University, Nizhnekamsk, \\ Russia
}

\begin{abstract}
This paper presents the results of calculations of velocity and temperature fields in the radiation chamber of an energy-intensive technological tubular oven during the combustion of methane in air using acoustic burners of floor flame. The calculation method is based on the joint numerical solution of difference analogs of three-dimensional equations of energy transfer by radiation, convection and turbulent thermal conductivity, the movement of flue gases and the methane combustion model in the air. The radiation selectivity of flue gases is taken into account using a six-band model. The paper contains a diagram showing the organization of a three-dimensional modelling of acoustic burners. It also represents the isotherms of combustion products, the lines of the velocity vectors in the radiation chamber, distributions of surface densities of heat fluxes to the heating surface.
\end{abstract}

\section{Introduction}

The main structural elements of radiation chambers of tubular ovens in petrochemical industry (conversion, reforming, pyrolysis, etc.) work at the limit of the possibilities of structural materials. Errors in estimating the local values of heat flow, temperature of the pipe wall and lining lead to an increase in the cost of operating the oven at best or the reduction of service life of the oven at worst.

In order to create energy-saving technologies and ensure the reliability of furnace structures it is necessary to analyze the effect of numerous operating and structural parameters on a complex heat and mass transfer process in the radiation chamber of the tubular oven. The major task is to improve the accuracy and specification of distributing the predicted characteristics of heat transfer in the combustion chamber. In our opinion for solving these problems it is better to use the differential method based on mathematical models of interrelated processes of radiation-convective heat transfer, turbulent movement of combustion products and burning fuel in the combustion chamber.

To obtain the required composition of the product at the outlet of the tubular reactors it is necessary to ensure a certain distribution of heat flows along the pipes. Different types of burners located on the side walls of the radiation chamber are used for this purpose. Acoustic burners are also used for burning the gas fuel at the side walls.

Figure 1 shows a simplified view of the fourth part of the radiation chamber of a tubular oven with acoustic burners located in three tiers on the side walls of the tubular oven and the coordinate system. A mixture of hydrocarbons and water vapor moves inside a vertical single-row pipe filled with catalyst; and it is heated to the required temperature due to the emission of combustion products and hot walls located symmetrically on both sides of the tubular screen. Flames from 18 burners lay out on the lining of side walls and create a three-dimensional temperature field in the radiation chamber.

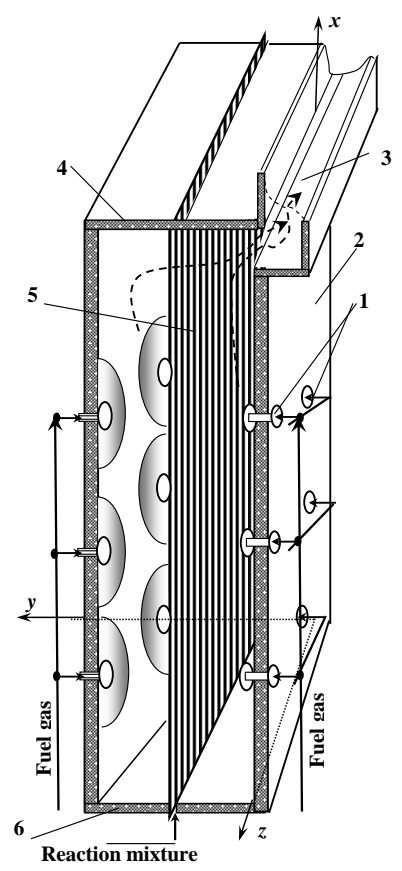

Fig. 1. Narrow chamber tube oven: 1 - burners; 2 - a flooring wall; 3 - the pass; 4 - chamber vault; 5 - tubular screen; 6 under the radiation chambers.

\footnotetext{
*Corresponding author: sadykov_av@mail.ru
} 
The scheme of an acoustic burner and a description of its work are available in [1,2]. Figure 2 shows a diagram explaining the three-dimensional simulation of the operation of the burner. A mixture of methane and air mixed partially due to the acoustic resonator enters the chamber from channel 4. Secondary air flows through channel 3 . These flows are reflected by disk 1 , mixing up, they are sent along the red-hot planking wall and burn in an almost invisible flame.

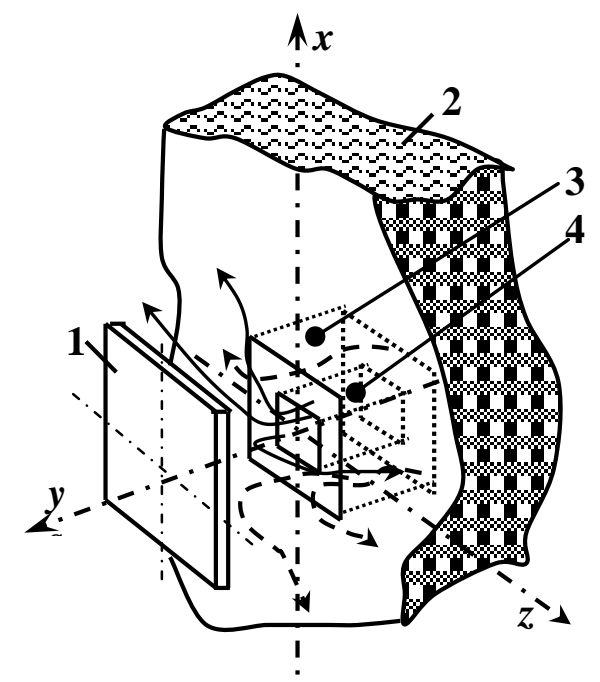

Fig. 2. The scheme of three-dimensional simulation of the operation of the burner for a differential grid with rectangular cells: 1 - reflecting disk; 2 - lined wall; 3 - channel for secondary air; 4 - channel for supplying partially mixed gas to combustion and air.

The possibility of thermal calculation of tube ovens with acoustic burners of a floor flame using the differential method [3] is shown in our works [1,2]. In recent years methods based on the joint numerical solution of the energy equation and gas dynamics equations have often been used to calculate furnace devices and heat exchangers. In particular, the paper [4] presents methods of numerical modeling tubular heat exchangers that are used in refineries and chemical plants. The mathematical model in [4] contains differential equations for the conservation of mass, momentum and energy. The paper [5] highlights the main achievements in computational fluid dynamics, discusses advanced scientific innovations.

\section{Description of the calculation method}

A detailed three-dimensional mathematical model is given in [1]. The complex heat and mass transfer in the radiation chamber is modelled by three-dimensional differential equations of energy, motion, continuity, k- $\varepsilon$ turbulence model, two-step model of methane combustion, radiation transport equation. The listed equations, except the radiation transport equation, can be represented in a generalized form

$$
\begin{aligned}
& \frac{\partial}{\partial x}(\beta u \Phi)+\frac{\partial}{\partial y}(\beta v \Phi)+\frac{\partial}{\partial z}(\beta w \Phi)= \\
& =\frac{\partial}{\partial x}\left(\Gamma_{\Phi} \frac{\partial \Phi}{\partial x}\right)+\frac{\partial}{\partial y}\left(\Gamma_{\Phi} \frac{\partial \Phi}{\partial y}\right)+ \\
& +\frac{\partial}{\partial z}\left(\Gamma_{\Phi} \frac{\partial \Phi}{\partial z}\right)+S_{\Phi}
\end{aligned}
$$

where the generalized variable $\Phi \equiv\left\{u, v, w, k, \varepsilon, m_{\Gamma}, m_{o k}\right.$, $T\} ; u, v, w$ are the components of the velocity vector of the combustion products along the $x, y$ and $z$ axes respectively; $S_{\Phi}$ is a source term. For each equation, presented in a generalized form, there are corresponding expressions for the exchange coefficients $\Gamma_{\Phi}$, for $\beta$, for source terms $S_{\Phi}$. For the algebraic approximation of equation (1) a difference grid of "chess" type is used.

The radiation transport equation is solved by the discrete ordinate method. The sets of angular coordinates and weight coefficients are borrowed from $[6,7,8]$. The Edwards wide band model is used to account for the selectivity of gas emissions [9]. Description of this model with reference to the original work is given in [3]. Spectral absorption coefficient of soot particles was calculated by the empirical formula given in [10].

The rate of chemical reaction is determined by the "Eddy Break -Up" model $[11,12]$. The values of the $k$ $-\varepsilon$ model constants are taken as recommended [13].

To determine the distribution of the mole fractions of $\mathrm{H}_{2} \mathrm{O}, \mathrm{CO}_{2}$ and $\mathrm{CO}$ in the volume of the combustion chamber, which are necessary for calculating the spectral absorption coefficients of gases, we used the model of methane combustion in two stages

$$
\mathrm{CH}_{4}+1.5 \mathrm{O}_{2} \rightarrow \mathrm{CO}+2 \mathrm{H}_{2} \mathrm{O}, \mathrm{CO}+0.5 \mathrm{O}_{2} \rightarrow \mathrm{CO}_{2}
$$

The papers $[3,14]$ give a detailed description of the features of the boundary conditions for the above listed equations, the method of difference approximation of differential equations and methods of numerical solution of the system of obtained algebraic equations by iterative method.

\section{Calculation results}

Three-dimensional calculations of heat and mass transfer were carried out for one-fourth of the tube oven chamber shown in figure 1 . The integration area is limited by a tubular screen, an end face of the chamber, a roof and a hearth, a flat wall, an exit section into the convection section of the oven (pass) and a plane of symmetry passing through the axes of the middle row along the height of the burners.

The half-chamber width along the $y$-axis was $1.3 \mathrm{~m}$, the depth along the $z$-axis was $10.5 \mathrm{~m}$, the height was 10 $\mathrm{m}$. The thickness of the lined walls was $0.45 \mathrm{~m}$, the density of their material was $1800 \mathrm{~kg} / \mathrm{m}^{3}$, the specific heat capacity was $1020 \mathrm{~J} /(\mathrm{kg} \cdot \mathrm{K})$, thermal conductivity coefficient $0.35 \mathrm{~W} /(\mathrm{m} \cdot \mathrm{K})$, the blackness degree was 0.42 for internal surfaces and 0.5 for external surfaces. The temperature of the outer surface of the walls of the 
furnace was assumed to be equal to $300 \mathrm{~K}$, and the temperature of the inner surfaces of the lined walls was determined by solving the heat conduction equation during an iterative process of solving the entire problem of complex heat transfer. The effective degree of blackness of the tubular screen is assumed to be 0.79 , and the temperature of the outer surfaces of the reaction tubes is set linearly increasing in height from 1000 to $1200 \mathrm{~K}$. The consumption of methane per burner was $0.022 \mathrm{~m}^{3} / \mathrm{s}$, and the air consumption with regard to the adopted $\alpha=1.07$ for burning was $0.224 \mathrm{~m}^{3} / \mathrm{s}$ under normal conditions for each burner. The temperature of the fuel gas and air entering the radiation chamber is assumed to be $323 \mathrm{~K}$.

Figure 3 shows the isotherms of combustion products in two mutually perpendicular sections of the furnace chamber of a tube oven (the digits in the figures are temperature values in $\mathrm{K}$ ). The main temperature changes of the combustion products occur in a fairly narrow layer within a range of $y=0.5 \mathrm{~m}$ from the wall. In the rest of the chamber, the temperature of the combustion products gradually decreases from 1400 to $1300 \mathrm{~K}$ when approaching the tubular screen. Then within the thermal boundary layer of the tubular reactors the temperature sharply decreases to the temperature of the outer walls of the pipes. Thus, there is a strong non-isothermal radiating volume of the radiation chamber, while some effective temperature throughout the volume of the furnace is taken in the normative calculation method. A is shown in figure $3 \mathrm{a}$, the higher the tiers of the burners; the more the area of burning is detached from the wall. This is apparently due to the influence of the upward flows of combustion products from the burners of the lower tiers.

Temperature and velocity fields of combustion products are formed due to the mutual influence and depending on the thermal radiation of flue gases and the furnace walls. Figure 4 shows the lines drawn as tangent to the velocity vectors of the flow of combustion products, in section, passing through the axes of the burners along the height of the radiation chamber of the oven. In this section one can notice areas of direct current, separated by areas of reverse currents. The first zone of direct current is formed by the combustion products of the burners of the lower tier. These lines run along the furnace floor and the tubular screen to the roof, continue to the flue gas collection tunnel at the junction to the convection part of the furnace. The same lines are approached by the lines of the velocity vectors directed from the burners along the $\mathrm{x}$ axis. The temperature of the combustion products along these lines gradually decreases from $2200 \mathrm{~K}$ in the area of intense combustion of methane to $1260 \mathrm{~K}$ at the exit from the radiation chamber. According to the data from the exploited tubular ovens for ethane pyrolysis, the temperature of the gases at the exit from the radiation chamber varies between $1253-1265 \mathrm{~K}$, which is quite consistent with the calculated data. The burners of the middle and upper tiers also form a zone of direct current, directed to the exit from the combustion chamber.

Some part of the radiation chamber is occupied by reverse current zones formed at the location of the burners. Reverse current zones have a relatively low temperature $(\sim 1450 \mathrm{~K})$, which is due to the cooling effect of the heating surface and remoteness from heat release areas. Suction of combustion products from the zones of reverse currents to the mouth of the burners contributes to the stability of the combustion gas-air mixture.

Figure 5 shows the distributions of surface densities of heat fluxes to the heating surface at different distances from the hearth along the depth of the furnace (i.e. along the $z$ axis). Because of the plane of symmetry the data are given for half of the radiation chamber. Near the mouths of the burners of the lower row $(x=1 \mathrm{~m} ; 2 \mathrm{~m})$ there are noticeable fluctuations in the densities of heat fluxes. The maxima of heat flux densities correspond to the axes of the burners. The largest deviations between their values reach $6 \mathrm{~kW} / \mathrm{m}^{2}$. Moving from the hearth, the distribution of the surface densities of heat fluxes along the depth of the furnace are aligned and at a distance of more than $8 \mathrm{~m}$ from the hearth, the oscillations become less noticeable. Figure 5also depicts the effect of limiting the combustion chamber surfaces on the distribution of

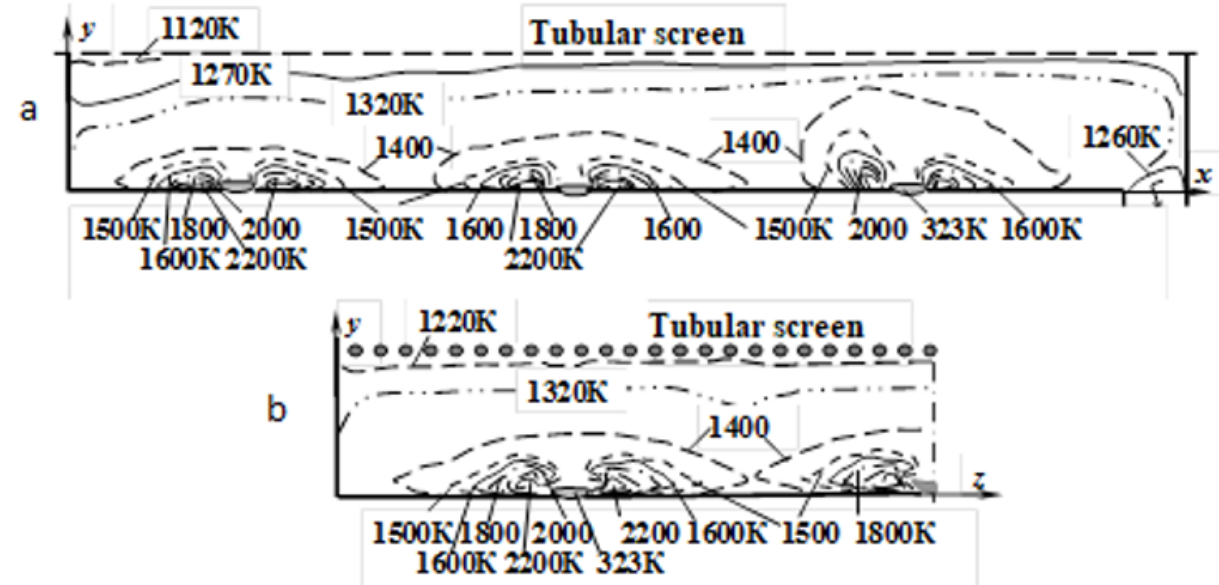

Fig. 3. Isotherms in two mutually perpendicular planes of the oven: (a) $z=1.75 \mathrm{~m}$, (b) $x=4.5 \mathrm{~m}$. 
heat fluxes. At a distance of $x=1 \mathrm{~m}$, the simultaneous influence of the end surface and the hearth is felt.

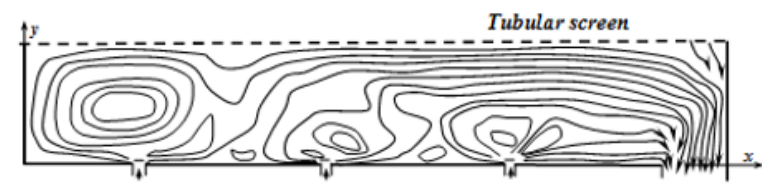

Fig. 4. Lines of velocity vectors in section passing through the axes of the burners.

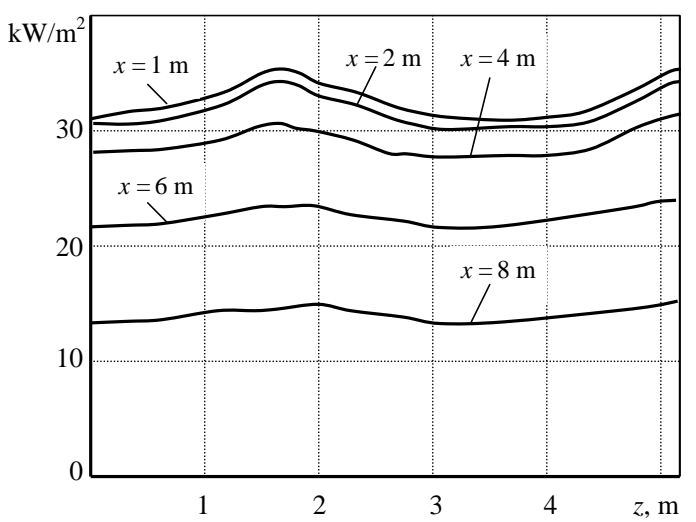

Fig. 5. The change in the surface densities of heat fluxes to a tubular screen along the depth of the radiation chamber.

Figure 6 shows the graphs of the temperature change of the combustion products by the height of the furnace with acoustic burners and for the oven PPR-1360 with injection burners located on the roof. For the oven PPR1360 in [15] there are experimentally obtained temperature values measured at a distance of $0.5 \mathrm{~m}$ from the side wall ovens. For this oven, the calculations were performed and the results are shown in the figure as solid line. As can be seen from figure 6, calculated and experimental temperature values for oven PPR-1360 are in good agreement. The temperature of the combustion products for the oven with acoustic burners change in a more complex way (dotted line), but closer to the transition to the convection section of the oven gas temperatures for both options become almost the same.

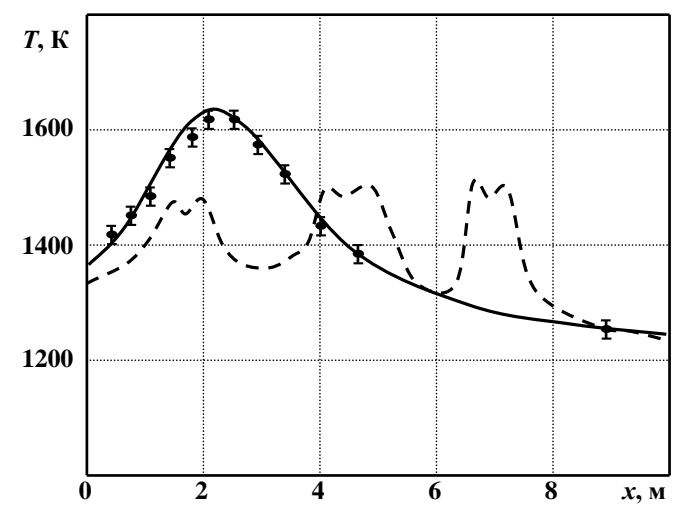

Fig. 6. Temperature change of combustion products on furnace chamber height: calculation for the PPR-1360; $\mathbf{\Phi}$ experiment [15]; - - - - calculation for the furnace with acoustic burners.

\section{Conclusions}

The conducted studies show that the differential method of thermal calculation of the furnace chambers can be used for numerical studies of complex heat exchange in the chambers of radiation of tube ovens with acoustic burners of a floor flame in a three-dimensional setting. Calculations show that when the floor flame burners are used the acoustic type fields of temperature and flow of combustion products are of a three-dimensional nature and temperature of the flooring wall changes in a complex way that makes it difficult using the zonal method of heat transfer calculation. In the normative method of thermal calculation of tubular ovens with radiant walls it is considered that the entire wall has the same temperature. The temperature of the combustion products at the outlet of the radiation chamber is consistent with the experimental data.

\section{References}

[1] D.B. Vafin, A.V. Sadykov, M.A. Butyakov, Calculation of a Three-Dimensional Temperature Field with Allowance for the Radiation Heat Exchange in Chambers of Tubular Ovens with Acoustic Burners High Temperature 4(4), 553-8 (2018)

[2] D.B. Vafin, A.V. Sadykov, Thermal calculation for a furnace with three - tiered near - wall burners Thermophysics and Aeromechanics 23(2), 281-8 (2016)

[3] D.B. Vafin, Complex Heat Transfer: Radiation Heat Transfer in Power Plants (Saarbrücken. Deutschland: LAP LAMBERT Acad. Publ) 251 (2011)

[4] D. Taler Numerical Modelling and Experimental Testing of Heat Exchangers (Springer, Cham) 588 (2019)

[5] J.S. Shang, 2019 Landmarks and new frontiers of computational fluid dynamics Advances in Aerodynamics AIA01 (2019)

[6] W.A. Fiveland, Three-Dimensional Radiative Heat Transfer Solutions by the Discrete-Ordinates Method Journal of Thermophysics and Heat Transfer 2(4), 309-16 (1988)

[7] J.S. Truelove, Discrete - Ordinate Solutions of the Radiation Transport Equation Journal of Heat Transfer 109, 1048-51 (1987)

[8] W.A. Fiveland, Comparison of Discrete Ordinates Formulations for Radiative Heat Transfer in Multidimensional Geometries J. Thermophys. Heat Transfer 9, 47-53 (1995)

[9] D.K. Edwards, Molecular gas band radiation Advanes in Heat Transfer (New York) 12, 115-93 (1976)

[10] G.L. Hubbard, Infrared Mean Absorption Coefficients of Luminous Flames and Smoke J. Heat Transfer 100, 235-39 (1978)

[11] B.R. Pai, S. Michelfelder, D.B. Spaldlng, Prediction of Furnace Heat Transfer with a ThreeDimensional Mathematical Model Int. J. Heat Mass Transfer 21(5), 571-75 (1978) 
[12] D.B. Spaldlng, Mathematical Models of Turbulent Flames: Review Combustion Science and Technology 13, 3-25 (1976)

[13] K.N. Volkov, Comparison of low-Reynolds models of turbulence with results of direct simulation for a channel flow Thermophysics and Aeromechanics. 12(3), 365-78 (2005)

[14] D.B. Vafin, A.V. Sadykov, Three dimensional mathematical model of external heat exchange in combustors of tube furnaces Vestn. Kazansk. Gos. Tekh. Univ. im. A.N. Tupoleva 2, 18-23 (2010)

[15] V.M. Sedelkin, Research and development of computational methods of heat exchange in tubular furnaces of the gas and petrochemical industry Doctoral (Tech.) Dissertation (Saratov Politekh. Inst.) 577 (1981) 